\title{
Prognostic factors and survival score for patients with anaplastic thyroid carcinoma: a retrospective study from a regional registry
}

\author{
Charles MARCHAND CRETY ${ }^{1}$, Madeline PASCARD ${ }^{1}$, Adeline \\ DEBREUVE-THERESETTE ${ }^{1}$, Leila Ettalhaoui ${ }^{1}$, Claire Schvartz $^{1}$, Mohamad Zalzali ${ }^{1}$, \\ Sara Bellefqih ${ }^{1}$, and Stéphanie Servagi-Vernat ${ }^{2}$ \\ ${ }^{1}$ Godinot Institute \\ ${ }^{2}$ Jean Godinot Institute
}

July 7, 2020

\begin{abstract}
BACKGROUND AND PURPOSE Anaplastic thyroid carcinoma (ATC) is the least common but most lethal of thyroid cancers despite various therapeutic options with limited efficacy. Some prognostic factors were identified in patients with ATC and a few patients survive for a relatively long time after modern intensive treatment. In order to help therapeutic decision-making, the purpose of this study was to develop a new prognostic score providing survival estimates in patients with ATC. METHODS Based on a multivariate analysis of 149 retrospectively analyzed patients diagnosed with ATC from 1968 to 2017 at a referral center, a propensity score was developed. A model was generated providing survival probability at 6 months and median overall survival estimates. RESULTS The median survival was 96 days. The overall survival rate was $35 \%$ at 6 months, $20 \%$ at 1 year and $13 \%$ at 2 years. Most of the patients (86\%) died within 17 month, $17 \%$ died within the first month, 35\% lived for $1-6$ months and $47 \%$ of the patients lived longer than 6 months after the initial consultation. The stepwise Cox regression revealed that the most appropriate death prediction model included metastatic spread, tumor size and age class as explanatory variables. This model made it possible to define three categories of patients with survival profiles which seems different: patients with no pejorative prognostic factor which had a survival probability at 6 months $=0,84$ (95\% CI: 0,69-1), patients with one or two pejoratives prognostics factors which have a survival probability at 6 months $=0,32(95 \% \mathrm{CI}: 0,22-0,46)$, and those with three pejoratives prognostics factors which had a survival probability at 6 months $=0,11$ (95\% CI: $0,018-0,71$ ). CONCLUSION Distant metastasis, age and primary tumor size are strong independent factors that affect prognosis in patients with ATC. Using these significant pretreatment factors, we developed a score to predict survival in these poor prognosis patients in order to provide easy-to-use tools for clinical practice. External validation in an additional dataset is needed for further outlooks.
\end{abstract}

\section{Keywords}

Anaplastic Thyroid Carcinoma, Prognosis, Propensity Score, Survival, Clinical Decision-Making

\section{Five key points}

1. The data used in this study come from a regional registry of patients with anaplastic thyroid carcinoma (ATC) treated from 1962 to 2017.

2. Prognosis of patients with ATC is very poor (in this study, median survival was 96 days)

3. Still, some patients with ATC (10-15\%) survive for a relatively long time after aggressive treatment.

4. Distant metastasis, advanced age and tumor size $>75$ millimeters are strong significant independent factors for predicting death in ATC patients. 
5. A prognostic score was developed to classify ATC patients into three groups, providing an easy-to-use tool for clinical practice.

\section{Background}

Although anaplastic thyroid carcinoma (ATC) is rare it is one of the most aggressive malignancies. This carcinoma accounts for $1.7 \%$ of all thyroid malignancies and one-half of all thyroid cancer deaths $(1,2)$. The median survival for ATC is 3-6 months with a one-year survival rate of $20 \%$ (3-6). Indeed, ATC most commonly presents in elderly patient with poor Performance Status making it difficult to tolerate an active therapeutic approach (7). Though, some patients survive for a relatively long time after aggressive treatment $(8,9)$. In such frail patients, aggressive treatment may worsen the quality of life and occasionally even shorten survival; therefore, the selection of patients who will benefit from such aggressive multimodal therapy seems important. Optimal ATC treatment is questionable due to lack of randomized trials; most studies validate the benefit of surgery. Although improved survival has been reported with post-operative radiotherapy, other reports questioned the benefit of radiotherapy $(10,11)$. Combined chemoradiotherapy was favored over radiation alone $(12,13)$. However, several series reported no benefit for chemotherapy $(6,14,15)$. Retrospective studies identified some prognostic factors such as age, gender, presence of acute symptoms, tumor size, multicentricity, metastatic spread, white blood cell level, blood platelet level and serum albumin level influenced survival of ATC patients $(13,16,17)$. Here, we reviewed data from 149 ATC patients in an attempt to identify subset of patients either that would benefit from more aggressive treatment strategy or those that are part of palliative care.

\section{Materials and Methods}

\section{Patients}

We reviewed the medical records of 149 patients with ATC treated at the Institut Godinot (Reims, France) between 1962 and 2017 (regional registry). We included all patients for whom ATC diagnosis had been confirmed in pathology. Other histologies such as malignant lymphoma, medullary carcinoma, or poorly differentiated insular carcinoma were excluded. For each patient, the following variables were collected : gender, age, metastatic spread, Eastern Cooperative Oncology Group-Performance Status (ECOG-PS), nodes involvement, tumor size, clinical symptoms (dysphagia, hoarseness and/or dyspnea), hematological markers before treatment (white blood cells count, lymphocyte count, neutrophil count, neutrophil-lymphocyte ratio and platelet count), patient latest status and treatment received (surgery, radiotherapy, chemotherapy).

\section{Statistical analysis}

All available data on the registry were used to maximize the power and generalizability of the results. Patient characteristics were reported as frequencies and proportions, and mean and standard deviation. KaplanMeier curve was used to visualize the cumulative probability of survival. Comparison between groups was performed only for variables with less than $50 \%$ missing data, using the likelihood ratio test. Continuous variables for which the hypothesis of log-linearity was not acceptable were dichotomized using a relevant clinical threshold or median and were included in this form in the multivariate model. A multivariate Cox proportional hazards model was used to examine overall survival (OS) after adjustments for clinical and demographic factors. A complete case analysis was undertaken. Each of the variables was entered into a stepwise regression (forward and backward) designed to minimize the Akaike Information Criteria (AIC). This allowed select a model taking into account $n$ prognostic variables $\left(\mathrm{X}_{\mathrm{i}}\right.$ à $\left.\mathrm{X}_{\mathrm{n}}\right)$ with $\mathrm{c}_{\mathrm{i}}$ categories. The patients were then divided into $\mathrm{c}_{1}{ }^{*} \mathrm{c}_{2}{ }^{*} \ldots{ }^{*} \mathrm{c}_{\mathrm{n}}$ categories according to the prognostic variables they presented. And finally, the categories were grouped together to propose a way of classifying patients in a simple way. Significance was determined to be $\mathrm{p}<0.05$ for all statistical tests.

\section{Results}

Baseline patient and tumor characteristics are shown in Table 1. Of the 149 patients, 93 (62.50\%) were women. The median age of patients was 72.9 years (range 20 to 91 years). $25 \%$ had an ECOG-PS score equal or more than 2. Clinical data was unknown in 67 cases. Of the 82 remaining patients, $46 \%$ had hoarseness, 
$44 \%$ had dysphagia and $34 \%$ dyspnea. Fifty eight patients had at least one of these three physical symptoms (71\%). At the time of diagnosis, 49 had metastatic spread (35\%) Nodes involvement data was missing in 72 cases. Of the 77 remaining patients, 56 had lymph nodes involvement (72\%). Tumor median size was 70 millimeters (range from 20 to 200 millimeters). Concerning hematological markers, $56 \%$ ( $\mathrm{n}=84$ ) was missing. The median count for white blood cells, neutrophil, lymphocyte and platelet was respectively $10.2 \mathrm{G} / \mathrm{l}$, $7.9 \mathrm{G} / \mathrm{l}, 1.3 \mathrm{G} / \mathrm{l}$ and $253 \mathrm{G} / \mathrm{l}$. The median neutrophil-lymphocyte ratio was 5.7 (mean = 7.8). Regarding management, $125(86 \%)$ underwent surgery, 98 (70\%) received radiotherapy (median 4500 cGy, range: 20007400 cGy), 55 (37\%) received chemotherapy. The median survival was 96 days as shown in Figure 1. One hundred thirty one patients died of their disease; twelve patients died of other causes. The overall survival rate at 6 months was $35 \%, 20 \%$ at 1 year and $13 \%$ at 2 years. Most of the patients (86\%) died within 17 month, $17 \%$ died within the first month, $35 \%$ lived for 1-6 months and $47 \%$ of the patients lived longer than 6 months after the initial consultation.

Univariate analysis of prognostic variables was carried out based on the length of survival of the 149 patients, and the results are shown in Table 2. Patients with metastatic spread at presentation, with nodes involvement with tumor size greater than 75 millimeters, age greater than 75 years old, ECOG-PS score equal or more than 1 and presence of at least one of clinical signs had a significantly shorter survival time. Dysphagia alone, dyspnea alone and hoarseness alone were not statistically significant. Multivariate analysis (Table 3) revealed that metastatic spread $(p=0,026)$, advanced age $(p=0,013)$ and tumor size $(p=0,026)$ were the most important and independent factors for predicting death from ATC.

The stepwise regression selected a model taking into account three binary prognostic variables: the metastatic stage, the age class and the size class of the lesion (less or more 75). The patients were divided into 8 categories according to the prognostic variables they presented. Then patients with one or two pejorative prognostic factors were grouped together resulting in three categories of patients: patients with no pejorative prognostic factors which had a survival probability at 6 months $=0,84$ (95\% CI: $[0,69-1]$ ) (median survival $=3769$ days), patients with one or two pejoratives prognostics factors which have a survival probability at 6 months $=0,32(95 \%$ CI: $[0,22-0,46])$ (median survival $=109$ days, $\mathrm{HR}=5,17[2,66 ; 10,02])$, and those with three pejoratives prognostics factors which had a survival probability at 6 months $=0,11$ (95\% CI: $0,018-0,71)$ (median survival $=48$ days, $\mathrm{HR}=11,94[4,66 ; 30,60]$ ). The Kaplan-Meier survival curves of the three groups are shown in Figure 2.

\section{Discussion}

Anaplastic thyroid carcinoma is a rare (1-2\%), extremely aggressive malignancy that has a very poor prognosis with median survival of $4-6$ months and a $20 \%$ one-year survival rate (1). In our study, the median survival time was 96 days and $128(86 \%)$ of the 149 patients died within 17 months of being diagnosed with ATC, which is extremely lethal. However, 18 (12\%) survived more than 4 years. A long remission therefore seems achievable in a limited number of patients with certain favorable factors at the time of diagnosis. These results are in line with the literature $(1,3,4,6,18,19)$. This study focused on pretreatment prognostic factors in order to provide assistance to the initial consultation with ATC patient. An increasing number of studies are investigating molecular prognostic factors that can potentially be identified at the time of diagnosis (20-26). Thus, high expression of Enhancer of Zeste Homolog 2 (EZH2), $\beta$-catenin, Anti-Apoptotic Protein MCL1 and PD-1 seems associated with a worse prognosis $(20,22,24,25)$. At the opposite, PAX8 positivity correlated with statistically significantly better overall survival (21). Epidermal Growth Factor Receptor (EGFR) is overexpressed in ATC and in vivo results show that gefitinib has significant antitumor activity against ATC in a subcutaneous nude mouse tumor model (26). However gefitinib did not demonstrate efficacy in patients with advanced thyroid cancer (27). Furthermore, between $20 \%$ and $50 \%$ of ATCs harbor activating B-Raf kinase (BRAF) V600 mutations with unknown prognostic significance (23,28). For patients with BRAF V600E-mutated ATC, combined BRAF plus MEK inhibition (dabrafenib plus trametinib) appears to be a promising new targeted therapy, demonstrating a high overall response rate, prolonged duration of response, and prolonged survival with manageable toxicity (29). However, the routine use of such targeted treatments or molecular markers does not seem feasible in the near future. 
We identified several studies in the last two decade that focused on non-molecular pretreatment prognostic factors in patients with ATC (11,13,30-41). Only one provides prognostic index based on data from 44 patients (40). The following factors were significantly associated with survival in patients suffering from ATC : metastatic disease (shown in nine studies or $64 \%$ of these studies), tumor size $(64 \%)$, age (50\%), white blood cells count (36\%), presence of acute symptoms (21\%), extrathyroidal invasion (14\%), lymph node involvement $(14 \%)$. The following variables showed association with survival in only one of these studies: blood platelet level, swollen thyroid gland, serum albumin level, ECOG-PS score, duration of symptoms and gender.

Concerning hematological markers, we also looked at neutrophil-to-lymphocytes ratio (NLR). A high NLR is associated with an adverse OS in many solid tumors $(43,44)$. Most studies use a cutoff ranging from 2 to 6 (45-52). In our study, median NLR was 5.2 (mean 7.8). This high median ratio is consistent with the fact that ATC patients have a poor prognosis. We failed to include NLR in the score due to missing values $(56 \%)$. To our knowledge, no studies have analyzed the prognostic value on the overall survival of NLR in ATCs. Still, one study showed that NLR can discriminate anaplastic thyroid cancer against poorly or well differentiated cancer with a 3.8 cutoff value (53).

While this study has the strength to include many patients from a regional registry, it suffers from the lack of data. This is mainly due to the long period of patient inclusion (from 1962 to 2017); most of the missing data came from patients treated prior 2000. Indeed, biological data, node status, ECOG-PS score and clinical signs failed to be collected in $58 \%, 46 \%, 46 \%$ and $45 \%$ of patients respectively. Thus, although significantly associated with overall survival in multivariate analysis, clinical signs and lymph node invasion were not included in the scoring system.

The final score took into account only the following three factors, making it easy to use in a practical way: distant metastases, advanced age and tumor size. Using this score, a new patient with ATC can therefore be classified into one of three groups, allowing physicians to guide management. If a patient experiences all these three pejorative factors (survival probability at 6 months $=11 \%$ ), management should be directed towards palliative care. On the contrary, if a patient has none of these factors (survival probability at 6 months $=84 \%$ ), the treatment should be as exhaustive as possible. Finally, in the delicate situation where a patient presents one or two of these factors (survival probability at 6 months $=32 \%$ ), a balance between aggressive treatment and preservation of quality of life should be found (54). External validation of the score is still recommended before using in clinical practice.

\section{Conclusion}

Anaplastic thyroid carcinoma is extremely lethal. Most patients with ATC derive only a small benefit from even aggressive treatments, particularly those with pretreatment poor prognostic factors. However, multimodal treatment might significantly improve overall survival in highly selected patients with favorable prognostic factors. In this study, we found that age, metastatic spread and primary tumor size are strong independent factors that affect prognosis in patients with ATC. Using these pretreatment factors, a score was developed to predict survival in order to provide easy-to-use tools for clinical practice before starting treatment for a patient with ATC. External validation in an additional dataset is needed for further outlooks.

\section{List of abbreviations}

ATC: anaplastic thyroid carcinoma

OS: overall survival

ECOG-PS: Eastern Cooperative Oncology Group Performance Status

NLR: neutrophil-to-lymphocytes ratio

EGFR: Epidermal Growth Factor Receptor

EZH2: Enhancer of Zeste Homolog 2 
PD-1: Programmed cell death 1

MLC1: Induced myeloid leukemia cell differentiation protein Mcl-1

PAX8: Paired box gene 8

BRAF: serine/threonine-protein kinase B-Raf

MEK: Mitogen-Activated Protein Kinase

\section{References}

1. Are C, Shaha AR 2006 Anaplastic Thyroid Carcinoma: Biology, Pathogenesis, Prognostic Factors, and Treatment Approaches. Ann Surg Oncol 13(4):453-64.

2. Chiacchio S, Lorenzoni A, Boni G, Rubello D, Elisei R, Mariani G 2008 Anaplastic thyroid cancer: prevalence, diagnosis and treatment. Minerva Endocrinol 33(4):341-57.

3. Lam K, Lo C, Chan K, Wan K 2000 Insular and Anaplastic Carcinoma of the Thyroid. Ann Surg 231(3):329-38 .

4. McIver B, Hay ID, Giuffrida DF, Dvorak CE, Grant CS, Thompson GB, A van Heerden J, Goellner JR 2001 Anaplastic thyroid carcinoma: A 50-year experience at a single institution. Surgery 130(6):102834.

5. Smallridge RC, Copland JA 2010 Anaplastic Thyroid Carcinoma: Pathogenesis and Emerging Therapies. J Clin Oncol 22(6):486-97.

6. Tennvall J, Lundell G, Wahlberg P, Bergenfelz A, Grimelius L, Åkerman M, Hjelm Skog AL, Wallin G 2002 Anaplastic thyroid carcinoma: three protocols combining doxorubicin, hyperfractionated radiotherapy and surgery. Br J Cancer 86(12):1848-53.

7. Ranganath R, Shah MA, Shah AR 2015 Anaplastic thyroid cancer. Curr Opin Endocrinol 22(5):387-91.

8. Sugitani I, Onoda N, Ito K, Suzuki S 2018 Management of Anaplastic Thyroid Carcinoma: the Fruits from the ATC Research Consortium of Japan. J Nippon Med Sch 85(1):18-27.

9. Ain KB 1999 Anaplastic thyroid carcinoma: a therapeutic challenge. Semin Surg Oncol 16:64-9.

10. Chen J, Tward JD, Shrieve DC, Hitchcock YJ 2008 Surgery and Radiotherapy Improves Survival in Patients With Anaplastic Thyroid Carcinoma. Am J Clin Oncol 31(5),460-4.

11. Kim TY, Kim KW, Jung TS, Kim JM, Kim SW, Chung KW, Kim EY, Gong G, Oh YL, Cho SY, Yi KH, Kim WB, Park DJ, Chung JH, Cho BY, Shong YK 2007 Prognostic factors for Korean patients with anaplastic thyroid carcinoma. Head \& Neck 29(8):765-72.

12. Mohebati A, DiLorenzo M, Palmer F, Patel SG, Pfister D, Lee N, Tuttle RM, Shaha AR, Shah JP, Ganly I 2014 Anaplastic Thyroid Carcinoma: A 25-year Single-Institution Experience. Ann Surg Oncol 21(5):1665-70.

13. Sugitani I, Miyauchi A, Sugino K, Okamoto T, Yoshida A, Suzuki S 2012 Prognostic Factors and Treatment Outcomes for Anaplastic Thyroid Carcinoma: ATC Research Consortium of Japan Cohort Study of 677 Patients. World J Surg 36(6):1247-54.

14. Ain KB, Egorin MJ, DeSimone PA 2009 Treatment of Anaplastic Thyroid Carcinoma with Paclitaxel: Phase 2 Trial Using Ninety-Six-hour Infusion. Thyroid 10(7):587-94.

15. Haigh P 2000 Anaplastic thyroid carcinoma. Curr Treat Options Oncol 1(1):353-537.

16. Lim SM, Shin SJ, Chung WY, Park CS, Nam KH, Kang SW, Keum KC, Kim JH, Cho JY, Hong YK, Chol BC 2012 Treatment Outcome of Patients with Anaplastic Thyroid Cancer: A Single Center Experience. Yonsei Med J 53(2):352.

17. Stavas MJ, Shinohara ET, Attia A, Ning MS, Friedman JM, Cmelak AJ 2014 Short Course High Dose Radiotherapy in the Treatment of Anaplastic Thyroid Carcinoma. J Thyroid Res 2014:764281.

18. Biganzoli L, Gebbia V, Maiorino L, Caraci P, Lirillo A 1995 Thyroid cancer: Different outcomes to chemotherapy according to tumour histology. Eur J Cancer. 31(13-14):2423-24.

19. Jereb B, Stjernsward J, Lowhagen T 1975 Anaplastic giant-cell carcinoma of the thyroid: A study of treatment and prognosis. Cancer 35(5):1293-5.

20. Abdulghani J, Gokare P, Gallant JN, Dicker D, Whitcomb T, Cooper T, Liao J, Derr J, Liu J, Gold- 
enberg D, Finnberg NK, El-Deiry WS 2016 Sorafenib and Quinacrine Target Anti-Apoptotic Protein MCL1: A Poor Prognostic Marker in Anaplastic Thyroid Cancer (ATC). Clin Cancer Res 22(24):6192203.

21. Becker N, Chernock RD, Nussenbaum B, Lewis JS 2014 Prognostic Significance of $\beta$-Human Chorionic Gonadotropin and PAX8 Expression in Anaplastic Thyroid Carcinoma. Thyroid 24(2):319-26.

22. Chintakuntlawar AV, Rumilla KM, Smith CY, Jenkins SM, Foote RL, Kasperbauer JL, Morris JC, Ryder M, Alsidawi S, Hilger C, Bible KC 2017 Expression of PD-1 and PD-L1 in Anaplastic Thyroid Cancer Patients Treated With Multimodal Therapy: Results From a Retrospective Study. J Clin Endocrinol Metab 102(6):1943-50.

23. Kebebew E, Weng J, Bauer J, Ranvier G, Clark OH, Duh QY, Shibru D, Bastian B, Griffin A 2007 The Prevalence and Prognostic Value of BRAF Mutation in Thyroid Cancer. Ann Surg. 246(3):466-71

24. Masudo K, Miyagi Y 2018 EZH2 Overexpression as a Useful Prognostic Marker for Aggressive Behaviour in Thyroid Cancer. In Vivo 32(1):25-31.

25. Rossi ED, Fadda G 2013 Diagnostic and Prognostic Role of HBME-1, Galectin-3, and $\beta$-Catenin in Poorly Differentiated and Anaplastic Thyroid Carcinomas. Appl Immunohisto M M 21(3):237-41.

26. Schiff BA 2004 Epidermal Growth Factor Receptor (EGFR) Is Overexpressed in Anaplastic Thyroid Cancer, and the EGFR Inhibitor Gefitinib Inhibits the Growth of Anaplastic Thyroid Cancer. Clin Cancer Res 10(24):8594-602.

27. Pennell NA, Daniels GH, Haddad RI, Ross DS, Evans T, Wirth LJ, Fidias PH, Temel JS, Gurubhagavatula S, Heist RS, Clark JR, Lynch TJ 2008 A Phase II Study of Gefitinib in Patients with Advanced Thyroid Cancer. Thyroid 18(3):317-23.

28. Begum S, Rosenbaum E, Henrique R, Cohen Y, Sidransky D, Westra WH 2004 BRAF mutations in anaplastic thyroid carcinoma: implications for tumor origin, diagnosis and treatment. Modern Pathol 17(11):1359-63.

29. Subbiah V, Kreitman RJ, Wainberg ZA, Cho JY, Schellens JHM, Soria JC, Wen PY, Zielinski C, Cabanillas ME, Urbanowitz G, Mookerjee B, Wang D, Rangwala F, Keam B 2018 Dabrafenib and Trametinib Treatment in Patients With Locally Advanced or Metastatic BRAF V600-Mutant Anaplastic Thyroid Cancer. J Clin Oncol 36(1):7-13.

1. Akaishi J, Sugino K, Kitagawa W, Nagahama M, Kameyama K, Shimizu K, Ito K, Ito K 2011 Prognostic Factors and Treatment Outcomes of 100 Cases of Anaplastic Thyroid Carcinoma. Thyroid 21(11):1183-9.

2. Besic N, Hocevar M, Zgajnar J, Pogacnik A, Grazio-Frkovic S, Auersperg M 2004 Prognostic factors in anaplastic carcinoma of the thyroid - a multivariate survival analysis of 188 patients. Langenbeck Arch Surg 390(3):203-8.

3. Glaser SM, Mandish SF, Gill BS, Balasubramani GK, Clump DA, Beriwal S 2016 Anaplastic thyroid cancer: Prognostic factors, patterns of care, and overall survival. Head \& Neck 38(S1):E2083-90.

4. Jiang JY, Tseng FY 2006 Prognostic factors of anaplastic thyroid carcinoma. J Endocrinol Invest 29(1):11-7.

5. Kihara M, Miyauchi A, Yamauchi A, Yokomise H 2004 Prognostic Factors of Anaplastic Thyroid Carcinoma. Surg Today 34(5):394-8.

6. Kwon J, Kim BH, Jung HW, Besic N, Sugitani I, Wu HG 2016 The prognostic impacts of postoperative radiotherapy in the patients with resected anaplastic thyroid carcinoma: A systematic review and meta-analysis. Eur J Cancer 59:34-45.

7. Liu TR, Xiao ZW, Xu HN, Long Z, Wei FQ, Zhuang SM, Sun XM, Xie LE, Mu JS, Yang AK, Zhang GP, Fan YF 2016 Treatment and Prognosis of Anaplastic Thyroid Carcinoma: A Clinical Study of 50 Cases. Plos One 11(10):e0164840.

8. Pacheco-Ojeda LA, Martínez, AL, Alvarez M 2001 Anaplastic thyroid carcinoma in ecuador: analysis of prognostic factors. Int J Surg 86(2):117-21.

9. Paunovic IR, Sipetic SB, Zoric GV, Diklic AD, Zivaljevic VR 2015 Survival and prognostic factors of anaplastic thyroid carcinoma. Act Chir Belg 115:62-7.

10. Sugitani I, Kasai N, Fujimoto Y, Yanagisawa A 2001 Prognostic Factors and Therapeutic Strategy for 
Anaplastic Carcinoma of the Thyroid. World J Surg 25(5):617-22.

11. Sun C, Li Q, Hu Z, He J, Li C, Li G, Tao X, Yang A 2013 Treatment and Prognosis of Anaplastic Thyroid Carcinoma: Experience from a Single Institution in China. Plos One 8(11):e80011.

12. Hamed RH, Sakr H, Lofty A 2018 Prognostic Factors of Anaplastic Thyroid Carcinoma: An Egyptian Single Institution Experience. Middle East J. Cancer 9(4):282-7.

13. Mei Z, Shi L, Wang B, Yang J, Xiao Z, Du P, Wang Q, Yang W 2017 Prognostic role of pretreatment blood neutrophil-to-lymphocyte ratio in advanced cancer survivors: A systematic review and metaanalysis of 66 cohort studies. Cancer Treat Rev 58:1-13.

14. Templeton AJ, McNamara MG, Šeruga B, Vera-Badillo FE, Aneja P, Ocaña A, Leibowitz-Amit R, Sonpavde G, Knox JJ, Tran B, Tannock IF, Amir E 2014 Prognostic Role of Neutrophil-to-Lymphocyte Ratio in Solid Tumors: A Systematic Review and Meta-Analysis. J Natl Cancer Inst 106(6):dju124.

15. Cho JK, Kim MW, Choi IS, Moon UY, Kim MJ, Sohn I, Kim S, Jeong HS 2018 Optimal cutoff of pretreatment neutrophil-to-lymphocyte ratio in head and neck cancer patients: a meta-analysis and validation study. BMC Cancer 18(1):969.

16. Deng M, Ma X, Liang X, Zhu C, Wang M 2017 Are pretreatment neutrophil-lymphocyte ratio and platelet-lymphocyte ratio useful in predicting the outcomes of patients with small-cell lung cancer? Oncotarget 8(23):37200-7.

17. Dolan RD, McMillan DC 2017 Neutrophil-to-lymphocyte ratio as a bladder cancer biomarker: Assessing prognostic and predictive value in SWOG 8710. Cancer 123(19):3855.

18. Ethier JL, Desautels D, Templeton A, Shah PS, Amir E 2017 Prognostic role of neutrophil-tolymphocyte ratio in breast cancer: a systematic review and meta-analysis. Breast Cancer Res 19(1):2.

19. Yin X, Wu L, Yang H, Yang HB 2017 Prognostic Significance of Neutrophil-to-Lymphocyte Ratio in Ovarian Cancer: A Systematic Review and Meta-Analysis of Observational Studies. Cell Physiol Biochem 41(6):2411-8.

20. Yang JJ 2015 Prognostic significance of neutrophil to lymphocyte ratio in pancreatic cancer: A metaanalysis. World J Gastroenterol 21(9):2807.

21. Yang Z, Gu JH, Guo CS, Li XH, Yang WC 2017 Preoperative neutrophil-to-lymphocyte ratio is a predictor of survival of epithelial ovarian cancer: a systematic review and meta-analysis of observational studies. Oncotarget 8(28):46414-24.

22. Yin Y, Wang J, Wang X, Gu L, Pei H, Kuai S, Zhang Y, ShangIIt Z 2015 Prognostic value of the neutrophil to lymphocyte ratio in lung cancer: A meta-analysis. Clinics 70(7):524-30.

23. Cho JS, Park MH, Ryu, YJ, Yoon JH 2015 The neutrophil to lymphocyte ratio can discriminate anaplastic thyroid cancer against poorly or well differentiated cancer. Ann Surg Treat Res 88(4):18792.

24. Nachalon Y, Stern-Shavit S, Bachar G, Shvero J, Limon D, Popovtzer A 2015 Aggressive Palliation and Survival in Anaplastic Thyroid Carcinoma. JAMA Otolaryngol. Head Neck Surg 141(12):1128.

Table 1. Patient and tumor characteristics of the 149 ATC patients.

\begin{tabular}{ll}
\hline Characteristics (patients eligible for analysis) & $\mathrm{N}(\%)$ \\
Age $(\mathrm{n}=149)$ & 72.9 years (range: 20-91) \\
Median & $85(57)$ \\
$<75$ years & $64(43)$ \\
$>75$ years & \\
Gender $(\mathrm{n}=149)$ & $56(38)$ \\
Male & $93(62)$ \\
Female & \\
ECOG-PS score $(\mathrm{n}=77)$ & $28(36)$ \\
0 & $30(39) ? \dot{\mathrm{i}} ?$ \\
1 & $19(25)$ \\
2 &
\end{tabular}




$\begin{array}{ll}\text { No signs } & 24(30) \\ \text { At least one clinical signs } & 58(70) \\ \text { Dyspnea } & 28(34) \\ \text { Dysphagia } & 36(46) \\ \text { Hoarseness }(\mathrm{n}=97) & 38(44) \\ \text { Tumor size } & \\ \text { Median }(\mathrm{mm}) & 70 \mathrm{~mm}(\text { range : 20-200) } \\ <75 \mathrm{~mm} & 51(51) \\ >75 \mathrm{~mm} & 46(46) \\ \text { Nodes involvement }(\mathrm{n}=77) & 56(72) \\ \text { Yes } & 21(27) \\ \text { No } & \\ \text { Distant metastasis }(\mathrm{n}=139) & 49(35) \\ \text { Yes } & 90(65) \\ \text { No } & \text { Mean } \\ \text { Hematological markers }(\mathrm{n}=65) & 10,4 \mathrm{G} / 1 \\ \text { White blood cells count } & 8,2 \mathrm{G} / 1 \\ \text { Neutrophil count } & 1,4 \mathrm{G} / \mathrm{l} \\ \text { Lymphocyte count } & 7,8 \\ \text { Neutrophil-lymphocyte ratio } & 270,8 \mathrm{G} / \mathrm{l} \\ \text { Platelet count } & \end{array}$

Abbreviations: ATC: anaplastic thyroid carcinoma, mm: millimeters, ECOG-PS: Eastern Cooperative Oncology Group-Performance Status.

Table 2. Univariate analysis for overall survival (OS).

\begin{tabular}{lll}
\hline & HR $(95 \%$ CI $)$ & P-value \\
Nodes involvement & $2,7(1,5-5)$ & $<0,001^{*}$ \\
Metastatic spread & $2,2(1,5-3,2)$ & $<0,001^{*}$ \\
At least one of local clinical signs & $1,7(1,1-2,8)$ & $0,025^{*}$ \\
Dysphagia & $1,5(0,94-2,3)$ & 0,093 \\
Dyspnea & $1,1(0,69-1,7)$ & 0,69 \\
Hoarseness & $1,2(0,79-1,9)$ & 0,35 \\
Age $(>75$ years $)$ & $2,1(1,5-3)$ & $<0,001^{*}$ \\
Tumor size $(>75 \mathrm{~mm})$ & $2,1(1,4-3,3)$ & $<0,001^{*}$ \\
ECOG-PS [?] 1 & $2,7(1,6-4,5)$ & $<0,001^{*}$ \\
\hline
\end{tabular}

Abbreviations: mm: millimeters, ECOG-PS: Eastern Cooperative Oncology Group-Performance Status, OS: overall survival.

Table 3. Multivariate Cox proportional hazard models for overall survival (OS).

\begin{tabular}{lll}
\hline & HR $(95 \% \mathrm{CI})$ & P-value \\
ECOG-PS score $>1$ & $1,9(0,8-4,7)$ & 0,16 \\
Metastatic spread & $2,0(1,1-3,7)$ & $0,026^{*}$ \\
Age $>75$ years & $2,2(1,2-4,0)$ & $0,013^{*}$ \\
At least one of local clinical signs & $3,0(1,1-8,7)$ & $0,038^{*}$ \\
Tumor size $>75 \mathrm{~mm}$ & $2,1(1,1-3,9)$ & $0,026^{*}$ \\
\hline
\end{tabular}


Abbreviations: mm: millimeters, ECOG-PS: Eastern Cooperative Oncology Group-Performance Status, OS: overall survival.

Figure 1. Overall survival (OS) of anaplastic thyroid cancer (ATC) patients (n=149).

Figure 2. Kaplan-Meier survival curves for patients with anaplastic thyroid cancer stratified by number of pejorative(s) prognostic(s) factor(s).
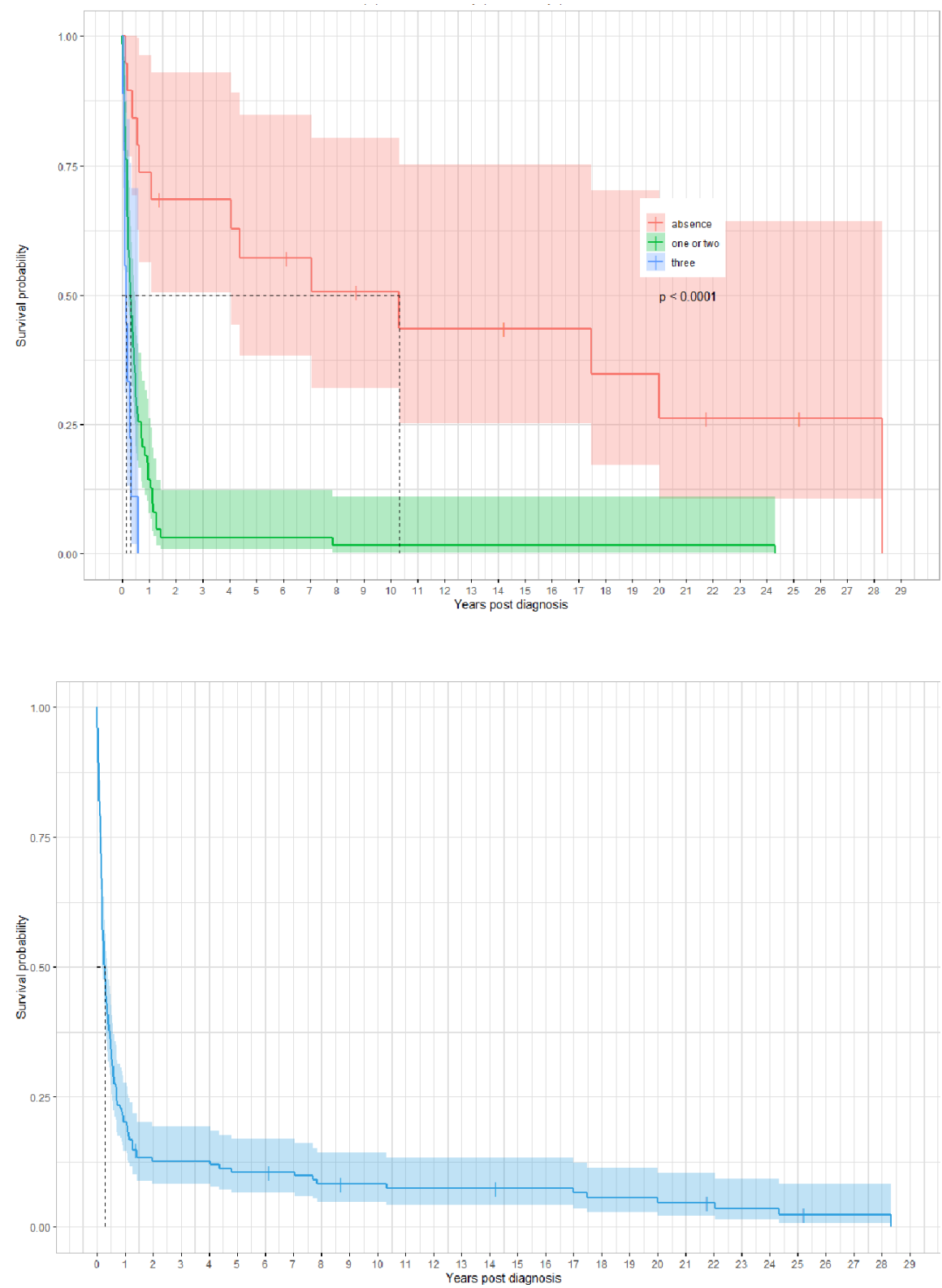